\title{
Sarcopenia in diabetic nephropathy: a cross-sectional study
}

\author{
MERAL ÇELİKER, MUSTAFA YAVUZ SELÇUK, SERDAR OLT \\ Adıyaman University, Faculty of Medicine, Department of Internal Medicine, Adıyaman, Turkey
}

\begin{abstract}
Objective. To investigate the relationship between sarcopenia and diabetic nephropathy.
Methods. 56 diabetic patients without complications, 50 diabetic patients with nephropathy, 53 healthy controls included in this present study. Demographic characteristics such as sex, age, anthropometric measurements such as weight, body mass index [BMI], hip circumference, waist circumference and upper arm circumference were measured. Sarcopenia diagnosis was based on European Working Group on Sarcopenia in Older People [EWGSOP] criteria which consist of hand grip strength, 6-meter walking test and muscle mass.

Results. The frequency of sarcopenia increased gradually from $15.1 \%$ in healthy control group to $21.4 \%$ in the diabetes group, and $34 \%$ in diabetic nephropathy group $\left(\mathrm{X}^{2}\right.$ for trend, $\left.\mathrm{p}=0.029\right)$. The frequency of sarcopenia was similar in diabetes and diabetic nephropathy group. However, the frequency of sarcopenia was higher in diabetic nephropathy than healthy controls $(\mathrm{OR}=2.89$, CI [1.11-7.51] in logistic regression).

Conclusion: In the present study, the prevalence of sarcopenia was higher in patients with diabetic nephropathy compared to healthy controls.
\end{abstract}

Key words: Sarcopenia, Diabetes Mellitus, Diabetic Nephropathies.

\section{INTRODUCTION}

Sarcopenia was first described by Rosenberg in 1989 as "involuntary muscle loss in the elderly and consequent reduction in muscle function". Recent studies have suggested that the definition of sarcopenia has had a change to "progressive reduction in age-related muscle function and mass" [1]. To be called sarcopenia; muscle mass, strength and physical performance must be assessed. The tests used in these evaluations are very diverse also the cost, ease of access and availability have shown differences between the way it has been used [2]. In a study by the Health and Nutrition Society, the prevalence of sarcopenia in the population over 60 years of age was $20 \%$ [3]. Along with the aging population, the prevalence of sarcopenia is predicted to increase. Female gender, low birth weight, advanced age, malnutrition, sedentary lifestyle, substance abuse and chronic diseases are risk factors for sarcopenia.

The prevention of the occurrence of sarcopenia is important because it minimizes the risk of falling and increases the ability to live independently. The existence of a healthy and trouble-free skeletal muscle means an independent life. Diabetes Mellitus $[\mathrm{DM}]$ is a chronic disease that tends to increase in prevalence all over the world and affects the quality of life and its duration in the negative direction due to its major complications. WHO estimates that, globally, 422 million adults aged over 18 years were living with diabetes in 2014 worldwide [4]. It is predicted that this number will reach 285 million in 2010 and reach 439 million by 2030 [5]. The frequency of diabetic nephropathy, which is one of the most important complications of DM, is rapidly increasing due to the increase in DM prevalence and the positive increase in diabetic patients during life. Diabetic nephropathy is the most common cause of end-stage renal disease [ESRD] in the world's general population, with diabetic patients predominantly in dialysis-requiring patients. In Type 2 DM patients, the prevalence of microalbuminuria was reported to be $25-40 \%$ after about 10 years of diagnosis. $20 \%$ of cases with nephropathy are reported to develop ESRD within 20 years. Therefore, early detection of diabetic nephropathy is important to prevent development of ESRD.

With aging process, muscle mass seems to be gradually decreasing. The muscle mass, which constitutes about one third of the total body weight at an early age, declines in advancing ages and falls to half when it reaches 75 years of age. Loss of muscle mass usually results in loss of strength in the back, arm, waist and leg muscles. Diabetic patients are prone to accelerated aging process and these individuals are at an early age with loss of muscle mass and strength due to various factors. 
Herein our aim was to examine the relationship between diabetic nephropathy and sarcopenia.

\section{MATERIALS AND METHODS}

This study was conducted in Adiyaman University Medical Faculty Internal Medicine outpatient clinics between January 2016 and October 2016 in a diabetic patient and control group over 50 years of age. Ethics Committee approval was obtained from the Ethics Committee of the Scientific Researches of Adiyaman University Faculty of Medicine on 03.05.2016 and numbered 12/03. Our work was done in harmony with the Helsinki declaration.

56 diabetic patients without complications, 50 diabetic patients with nephropathy, 53 age and sex matched healthy controls were included in this present study. Demographic characteristics such as sex, age, anthropometric measurements such as weight, body mass index [BMI], hip circumference, waist circumference, waist circumference and upper arm circumference were measured.

The percentage of muscle mass, percentage of fat and visceral fat amount were evaluated by bioelectrical impedance method. Skin thickness was measured with the help of a caliper. Patients' physical performance was assessed by the 6-meter walking test. Muscle forces were analyzed by hand dynamometer as hand grip strength. Anthropometric, bioelectrical impedance measurements and 6-meter walking test were performed by the same investigator.

Serum creatinine, glomerular filtration rate and 24-hours urinary albumin excretion were evaluated for the diagnosis of nephropathy.

The definition of Sarcopenia by the European Working Group on Sarcopenia in Older People [EWGSOP, Sarcopenic study group] is linked to objective criteria. According to the EWGSOP, the diagnostic criteria for Sarcopenia are as follows:

1. Low muscle mass

2. Low muscle strength

3. Reduced physical performance

In the case of Sarcopenia, in addition to criteria 1 , the presence of criteria 2 or criteria 3 is required. Based on these diagnostic criteria, sarcopenia diagnosis was based on objective criteria and at the same time diagnosis was not limited to muscle mass. In our study, muscle mass was calculated by the bioelectrical impedance method [Omron body composition monitor, Omron Healthcare $\AA]$. In order to standardize measurements, all measurements were taken 2 hours after breakfast or before lunch. Measurements were not made after too much water ingestion and after intense exercise. Measurements were made at the patient's feet and hands in a nude 900 position, holding the hand electrodes at 900 flexors and hands, without bringing knee flexion. Measurements were made three times, arithmetic averages were taken and the value obtained was used in the analyses. Muscle mass was obtained by multiplying the body muscle percentage found by BMI. The body fat percentage was also calculated at the same time as the Omron body composition monitor. Different results have been reported for low muscle mass threshold values.

Muscle strength was assessed using a digital hand dynamometer [Baseline smedley digital hand dynamometer]. Based on the work done by Wang et al. [6], hand grip strength was considered to be under $26 \mathrm{~kg}$ for males and $18 \mathrm{~kg}$ for females. After informing about the patient's dynamometer, they were allowed to try 3 times. Afterwards, they were asked to squeeze the hand dynamometer with their maximum power, three times in total, and the best results were based.

Patients' physical performance was assessed using a 6-meter walking test. The 6-meter walking test was reported to be successful in evaluating physical performance. Accordingly, it is defined as a slow walking less than $1.0 \mathrm{~m} / \mathrm{sec}$ in the $6 \mathrm{~m}$ walking test. The test was conducted on a flat surface, where patients were asked to walk without any constraint on the desired distance. The use of the assistive device was allowed if the patient was using it before the test. The walking test was performed twice in our study and the averages of the measurements were taken.

\section{Statistical analysis}

Statistical analyses were performed using the SPSS version 20.0 [IBM ${ }^{\circledR}$ Inc, Chicago, USA] package program. Descriptive statistics is summarized as number, percentage, mean and standard deviation. The suitability of the variables for the normal distribution was investigated using visual [histogram and probability graphs] and analytical methods [Kolmogorov-Smirnov, Shapiro-Wilk tests]. Numerical variables determined according to normal distribution were compared between two groups using Independent $\mathrm{T}$ test, and using One-Way ANOVA test between three groups. The homogeneity of the variances was assessed by the Levene test. Post-hoc analyses were performed with the Bonferroni test in cases with significant differences. 
Numerical variables without normal distribution were compared between two groups using Mann Whitney U test and three or more groups Kruskal Wallis test. Chi-square analysis was used to compare the nominal data. Logistic regression (enter method) with sarcopenia as dependent variable was used. Comparisons under the $\mathrm{p}$ value of 0.05 were considered statistically significant in the statistical analyses in the study.

\section{RESULTS}

A total of 159 participants were included in the study. Of these, 56 [35.2\%] had diabetes mellitus [diabetes group], 50 [31.4\%] had diabetes mellitus and diabetic nephropathy, and 53 had not diabetes mellitus (control group) [33.3\%]. The mean age of the patients was $60.9 \pm 6.9$ years [median 61 years, range 50-81 years]. The mean age of diabetes group was $61.7 \pm 7.2$ years, $61.7 \pm 6.9$ of diabetic nephropathy group and $59.4 \pm 6.5$ years of control group. The groups were similar in terms of age $[\mathrm{p}=$ $0.151] .35 .2 \%[\mathrm{n}=56]$ of the participants were male. Mean duration of diabetes was $8.3 \pm 6.9$ years [median 7, range 0-30 years]. The mean duration of diabetes in the diabetes group was $6.7 \pm 6.2$ years, and in the diabetic nephropathy group it was $10.0 \pm$ 7.3 years. The average duration of diabetes in the diabetic nephropathy group was higher than in the diabetes group [p $=0.014]$. The mean BMI of the diabetes group was $31.4 \pm 5.1$, the diabetic nephropathy group was $31.3 \pm 6.4$, and the control group was $31.0 \pm 5.7$. The groups were similar in terms of BMI $[\mathrm{p}=0.931]$.

The groups were similar in terms of tight, waist, hip and upper arm circumferences (Table 1).

Also, there were no differences concerning the skin thickness, mean fat percentage, and mean visceral fat amount (Table 2).

There was a statistically significant difference in percentage of muscle mass between the groups $[p=0.043]$. In the post-hoc analses performed, the percentage of muscle mass in the diabetic nephropathy group was lower than in the control group $[p=0.045]$. There was no difference in percentage of muscle mass among the other groups. When the gender effect was evaluated, the percentage of muscle mass of male participants [34.5 \pm 3.8$]$ was significantly higher than that of females $[25.5 \pm$ $2.4][\mathrm{p}<0.001]$ (Table 3).
There was no statistically significant difference between the groups in terms of total muscle mass $[p=0.069]$. When sex effect was evaluated, it was seen that the total muscle mass of male participants $\left[9.5 \pm 1.2 \mathrm{~kg} / \mathrm{m}^{2}\right]$ was significantly higher than that of females $\left[8.3 \pm 1.2 \mathrm{~kg} / \mathrm{m}^{2}\right][p<0.001]$.

There was a statistically significant difference between the groups in terms of hand grip strength $[p=0.015]$. In the post-hoc analyses performed, the grip strength of the diabetic nephropathy group was found to be lower than the control group [p = $0.023]$. There was no difference in hand grip strength among the other groups. When the sex effect was evaluated, it was seen that the hand grip power of male participants $[32.3 \pm 9.7]$ was significantly higher than that of females [17.7 \pm 5.4$][p<0.001]$.

There was a statistically significant difference in walking time between the groups $[p<0.001]$. In the post hoc analyses performed, the gait duration of the control group was lower than of the diabetes group $[p=0.003]$ and the duration of the diabetes group was shorter than of the diabetic nephropathy group [ $p<0.001]$. When gender effect was evaluated, it was seen that walking time of male participants $[7.9 \pm 3.2]$ was significantly shorter than that of females $[10.6 \pm 3.7][p<0.001]$. The mentioned parameters were summarized in Table 3 .

The prevalence of Sarcopenia was $23.3 \%$ in all patients. The prevalence of sarcopenia in the diabetes group was $21.4 \%$, in the diabetic nephropathy group it was $34 \%$ and in the control group $15.1 \%$ (Figure 1).

The prevalence of Sarcopenia in the diabetic nephropathy group was not significantly different from that of the diabetes group [ $p=0.147]$, but it was statistically significantly higher than that of the control group $[p=0.025]$. In terms of the prevalence of sarcopenia, the difference between diabetes and control groups was not statistically significant $[p=0.147]$. The mentioned parameters were summarized in Table 4.

The frequency of sarcopenia increased gradually with the severity of disease (control without diabetes, diabetes without complications, diabetes with nephropathy: $X^{2}=33.3$ for trend, $p=0.029$, Table 5). The presence of diabetes with nephropathy increased 2.89 times the risk of sarcopenia compared to healthy controls. 
Table 1

Comparison of thigh circumference, waist circumference, hip circumference and upper arm circumference between groups

\begin{tabular}{lcccc}
\hline $\begin{array}{c}\text { Circumference } \\
(\mathbf{c m})\end{array}$ & $\begin{array}{c}\text { Diabetes group } \\
\mathbf{n}=\mathbf{5 6}\end{array}$ & $\begin{array}{c}\text { Diabetic nephropathy } \\
\text { group } \mathbf{n}=\mathbf{5 0}\end{array}$ & $\begin{array}{c}\text { Control group } \\
\mathbf{n}=\mathbf{5 3}\end{array}$ & P value \\
\hline Thigh & $37.3 \pm 4.5$ & $37.4 \pm 6.3$ & $37.9 \pm 5.1$ & 0.852 \\
\hline Waist & $106.6 \pm 10.1$ & $105.2 \pm 11$ & $102.5 \pm 10.4$ & 0.135 \\
\hline Hip & $107 \pm 8.9$ & $108 \pm 12.9$ & $107 \pm 9.3$ & 0.870 \\
\hline Upper Arm & $33.8 \pm 6.4$ & $32.9 \pm 4.5$ & $33 \pm 4.4$ & 0.630 \\
\hline
\end{tabular}

Table 2

Comparison of skin thickness, fat percentage and visceral fat amount among groups

\begin{tabular}{lcccc}
\hline \multicolumn{1}{c}{ Parameters } & $\begin{array}{c}\text { Diabetes } \\
\text { group } \mathbf{n}=\mathbf{5 6}\end{array}$ & $\begin{array}{c}\text { Diabetic nephropathy } \\
\text { group } \mathbf{n = 5 0}\end{array}$ & $\begin{array}{c}\text { Control } \\
\text { group n }=\mathbf{5 3}\end{array}$ & P value \\
\hline Skin thickness $\mathbf{( c m )}$ & $27.8 \pm 7.9$ & $25.5 \pm 8.3$ & $26.2 \pm 8.2$ & 0.339 \\
\hline Fat percentage \% & $36.8 \pm 10.3$ & $37.2 \pm 9.7$ & $33 \pm 12.4$ & 0.099 \\
\hline Visceral fat percentage \% & $12.5 \pm 3.6$ & $11.3 \pm 3$ & $12.7 \pm 5.8$ & 0.246 \\
\hline
\end{tabular}

Table 3

Comparison of muscle mass percentage, total amount of muscle mass, hand grip strength and walking period between groups

\begin{tabular}{lcccc}
\hline \multicolumn{1}{c}{ Parameters } & $\begin{array}{c}\text { Diabetes } \\
\text { group } \mathbf{n}=\mathbf{5 6}\end{array}$ & $\begin{array}{c}\text { Diabetic nephropathy } \\
\text { group } \mathbf{n}=\mathbf{5 0}\end{array}$ & $\begin{array}{c}\text { Control } \\
\text { group n } \mathbf{5 3}\end{array}$ & P value \\
\hline Muscle mass percentage \% & $28.2 \pm 4.9$ & $27.7 \pm 4.6$ & $30.1 \pm 5.9$ & $\mathbf{0 . 0 4 3}$ \\
\hline Total muscle mass $\left(\mathbf{k g} / \mathbf{m}^{\mathbf{2}}\right)$ & $8.7 \pm 1.1$ & $8.5 \pm 1.5$ & $9.1 \pm 1.3$ & 0.069 \\
\hline Hand grip strength $(\mathbf{k g})$ & $24 \pm 11.2$ & $19.7 \pm 8.9$ & $25.1 \pm 9.2$ & $\mathbf{0 . 0 1 5}$ \\
\hline Walking period (s) & $9.6 \pm 3.5$ & $12.2 \pm 3.5$ & $7.3 \pm 2.6$ & $<\mathbf{0 . 0 0 1}$ \\
\hline
\end{tabular}

Table 4

Comparison of the Sarcopenia frequency between the groups

\begin{tabular}{lll}
\hline Diabetes group & Diabetes nephropathy group & 0.147 \\
\hline Diabetes group & Control group & 0.393 \\
\hline Diabetes nephropathy group & Control group & $\mathbf{0 . 0 2 5}$ \\
\hline
\end{tabular}

Table 5

Binary logistic regression analysis results for sarcopenia in the groups

\begin{tabular}{|l|c|c|c|c|}
\hline & B & P value & O.R & 95\% Cl for O.R \\
\hline Diabetic nephropathy - Control & 1.06 & $\mathbf{0 . 0 2}$ & 2.89 & $1.11-7.51$ \\
\hline Diabetic nephropathy - Diabetes without complication & 0.42 & 0.39 & 1.53 & $0.57-4.11$ \\
\hline Gender (Female) & 0.20 & 0.60 & 1.22 & $0.57-2.64$ \\
\hline
\end{tabular}

\section{DISCUSSION}

A gradual increase in sarcopenia, which was suggested by Rosenburg in 1989 and which indicates age-related decline in muscle mass, EWSGOP reported that muscle mass and physical performance should be taken into consideration in addition to muscle masses that define sarcopenia. In our study, EWSGOP criteria [bioelectrical impedance method [BIA]] were found to be $21.4 \%$ in patients without diabetic nephropathy, $34 \%$ in patients with diabetic nephropathy and $15.1 \%$ in the control group [ $25 \%$ in males and $22.3 \%$ in females].

Sarcopenia has been frequently studied in the general population, especially in elderly individuals.
From the combined criterion recommended by the Sarcopenia EWGSOP or the "Asian Working Group for Sarcopenia" [AWSG], it has been extensively assessed separately for muscle strength, muscle mass or physical performance in the majority of studies. Studies using these combined criteria to study sarcopenia in diabetic patients are very limited. Among these studies, the study by Wang et al. reported $14.8 \%$ of Sarcopenia and $14.4 \%$ of presarcopenia in diabetic patients [7]. These ratios, which were significantly higher than the control group, were $11.2 \%$ and $8.4 \%$ in the control group, respectively. Kim et al. reported that the frequency of sarcopenia was $15.7 \%$ in diabetic patients and $6.9 \%$ in the control group [8]. In our study, the 
prevalence of sarcopenia was $21.4 \%$ in diabetic patients and $15.1 \%$ in the control group.

Although the frequency of sarcopenia in diabetic patients was higher than in the healthy control group in our study, the difference was not statistically significant. This was probably due to the small number of patients. However, the frequency of sarcopenia in diabetic nephropathy group was significantly higher than in the healthy control group.

Insulin, a anabolic hormone, stimulates protein synthesis and therefore muscle synthesis. Protein degradation and synthesis in the skeleton continues to be continuous. When there is a defect in the insulin signaling pathway, muscle synthesis may be reduced. Functional disability, muscle weakness and loss of performance are frequently encountered in diabetic patients. Therefore, it is thought that the frequency of sarcopenia increases in diabetic patients. However, the number of studies examining sarcopenia in diabetic individuals is limited. In a study conducted by Kalyani et al. In the Baltimore Longitudinal Study of Aging, it was stated that hyperglycemia assessed by $\mathrm{HbA} 1 \mathrm{C}$ is associated with decreased muscle strength [assessed by knee extensor muscle strength] [9]. In this study, peripheral polyneuropathy was also found to mediate sarcopenia-diabetes association. In a study by Park et al. "Health, Aging, and Body Composition [Health $A B C]$ ", diabetic individuals showed a greater knee extensor strength reduction than non-diabetic individuals [10]. In this Park's et al. study, which was the follow-up period of 3 years, muscle strength, muscle mass and muscle quality decreased with diabetes. Another study by the same group reported that diabetic women showed a 2-fold reduction in cross-sectional muscle area compared to non-diabetic women [11]. In a study conducted by Sayer et al. it was reported that muscular strength and physical function losses were higher in males with new diabetes mellitus than in nondiabetics [12]. It is thought that the decrease in muscle mass and muscle quality in diabetic patients starts from the early stages of diabetes. Although there are studies examining the relationship between diabetes and sarcopenia, as far as we know, there are no studies examining the prevalence of sarcopenia in diabetic nephropathy. Therefore, it has been shown for the first time in our study that the prevalence of sarcopenia increases in the presence of nephropathy. The prevalence of sarcopenia in diabetic nephropathy was significantly higher than in the healthy control group $[p=0.025]$, even though the frequency was not higher than in diabetic patients without nephropathy [ $p=0.147]$. Some possible explanations for this relationship can be made. Diabetic nephropathic glucose is linked to proteins, lipids, and nucleic acids by nonenzymatic pathways to form advanced glycation end products [AGEs]. AGE formation has also been shown to mediate the pathogenesis of sarcopenia. AGEs accumulate in skeletal muscles and cartilage tissue, causing joint stiffness and muscle strength to decrease. It is known that the production of oxidative stress and reactive oxygen radicals responsible for the pathogenesis of nephropathy causes DNA and protein damage. Wang et al. [7] reported that the reduction of these associated IGF-1 levels was effective. It has previously been expressed that impairment of muscle function with reduced IGF-1 levels. On the other hand, it is known that sarcopenia is mediated by neuropathy in diabetic patients. Increased frequency of peripheral neuropathy has been shown in the presence of diabetic nephropathy. Since nephropathy is associated with accumulation of toxic metabolites in muscle proteins, it also results in defects in muscle quality and protein architecture. This can result in decreased muscle function. Diabetic nephropathy and sarcopenia may be thought to be mediated by neuropathy. When considered together, it can be said that the pathogenesis of diabetes and nephropathy is similar to the pathogenesis of sarcopenia at the same time. On the other hand, although nephropathy is seen even in the early stages of diabetes, the frequency increases in the following periods.

Fukuda et al. reported that the prevalence of sarcopenia increased in patients with diabetic retinopathy [13]. Kalyani et al. showed a similar association in patients with with diabetic neuropathy [9]. To our knowledge, in our study, the relationship between diabetic nephropathy and sarcopenia was investigated for the first time. All of these are microvascular complications of diabetes and it can be said that the sarcopenia risk increases with microvascular complications. For this reason, taking preventive measures for patients at risk, preventing the occurrence of sarcopenia, especially in elderly patients, will increase the independence in terms of functioning, especially considering the high risk of sarcopenia in microvascular diabetic complications.

In literature, sarcopenia frequency has been reported at different rates in different populations. There were some reasons why the reported prevelances showed great variability. In some studies, 
low muscle mass was defined as having under 2 SD of adult individuals, while in some studies threshold values were established using muscle masses of elderly individuals. Total fat-free body mass was also preferred when evaluating the frequency of sarcopenias beside muscle mass. While appendix muscle mass is preferred in some of the studies using skeletal muscle, total skeletal muscle mass is preferred in some of the studies. On the other hand, the use of different diagnostic criteria [muscle mass, muscle strength, physical performance, etc.] and the use of different threshold values contributes to a wide range of reported sarcopenia frequency by different methods of evaluation of sarcopenia [DXA, BIA etc.]. In addition, it can be considered that the geography affected also affects the frequency of sarcopenia.

In the study performed by the EWGSOP group, sarcopenic frequency was found to be $24.2 \%$ in males and $39.0 \%$ in females when assessed by bioelectrical impedance analysis. In the same study, when the DXA method was chosen for the evaluations, the prevalence decreased to $13.2 \%$ for males and $3.2 \%$ for females. In the study conducted by the AWSG group in $2014,7.1 \%$ of males and $19.8 \%$ of females were reported using the BIA method [14]. These findings are close to our results.

In our study, the muscle mass, walking speed and muscle strength threshold values used in the evaluation of sarcopenia were based on the results of Bahat et al.'s work in our country [15]. The threshold values found in the study of Bahat et al. were reported to be close to the threshold values reported from France, Spain and Taiwan, although the mean values were somewhat higher than those of the other studies, and the sensitivity and specificity of the proposed threshold values were high.

In the elderly, systemic conditions or risk factors associated with sarcopenia, which are important causes of disability, have been identified. In our study, the higher frequency of sarcopenia was related to advanced age, higher HbA1C levels, presence of nephropathy and low muscle mass.

Landi et al. [16] reported that sarcopenia was seen more frequently in males, but on the contrary, $\mathrm{Yu}$ et al. reported that females were seen more frequently [17]. In our study, total muscle mass, hand grip strength and walking speed were lower than expected in males, but the prevalence of sarcopenia was similar [25\% vs. $22.3 \%$ ].
It has been suggested that there are various mechanisms under which the increase in the frequency of sarcopenia with age is seen. These factors include changes in growth hormone, insulin, estrogen and testosterone levels, increased proinflammatory cytokines, increased cell apoptosis, qualitative and quantitative reduction of nutrition, and neurogenic causes. Number of motor units decreases with age and it is known that there is a decrease in the diameter of the type II fibers with the increase in the age, and at the same time the ratio of type I fiber increases.

In our study, it was shown that body mass index was lower in the presence of sarcopenia. This relationship is confirmed by Waters and Baumgartner [18-19]. Sarcopenic obesity has been suggested by Kohara K [20] as a sign of simultaneous obesity with sarcopenia. Both obesity and sarcopenia have been reported to have an impact on metabolic disorders, morbidity and mortality. When taken together, it has been suggested that these effects potentiate each other. Complex pathophysiological mechanisms such as proinflammatory cytokines, increased oxidative stress, increased insulin resistance, and decreased physical activity have been implicated in the relationship between sarcopenia and obesity.

Our work had some limitations. Firstly our study was a descriptive type of work and therefore it cannot demonstrate cause-effect relationships. Secondly, it had small sample size and did not evaluate the relationship between sarcopenia and smoking, blood pressure and serum lipids.

\section{CONCLUSION}

As far as we know in our study, we examined the frequency of sarcopenia in patients with diabetic nephropathy for the first time in the literature. It has been shown that sarcopenia, which has an increased frequency in the elderly, is also accompanied by diabetic nephropathy more frequently. Increased risk of stroke, fracture, gait disturbance or difficulty, sarcopenia associated with disability, infection, reduced quality of life and increased mortality is further heightened when the prevalence of the elderly population and diabetes increases. Sarcopenic formation may be prevented or delayed by protective measures such as: tight glycemic control, and physical activity programs.

Conflict of interest: The authors declare there is no conflict of interest.

Obiectiv. Investigarea relației dintre sarcopenie şi nefropatia diabetică.

Metode. Au fost incluşi în studiu 56 de pacienți diabetici fără complicații, 50 de pacienți cu diabet şi nefropatie şi 53 de martori sănătoşi. Au fost luate date 
demografice şi au fost făcute măsurători antropometrice (greutate, indice masă corporală, circumferința taliei, circumferința brațului). Diagosticul sarcopeniei s-a fãcut pe baza criteriilor date de Grupul de Lucru European - EWGSOP care include forța de prehensiune a mâinii, testul de mers 6 metri şi masa musculară.

Rezultate. Prevalența sarcopeniei a crescut gradat de la $15.1 \%$ la pacienții sănătoşi la 21.4\% la grupul de pacienti diabetici fără comorbidități la $34 \%$ din pacienții cu nefropatie diabetică (test $X^{2}$ trend, $p=0.029$ ). Frecvența sarcopeniei a fost similară la pacienții cu diabet fără comorbidități şi cei cu nefropatie diabetică. Totuşi frecvența sarcopeniei la pacienții din grupul cu nefropatie diabetică a fost semnificativ statistic mai mare comparativ cu martorii sănătoşi $(O R=2.89, C I$ 95\% [1.11-7.51] în modelul de regresie logistică).

Concluzii. Prevalența sarcopeniei a fost mai mare la pacienții cu nefropatie diabetică comparativ cu martorii sănătoşi.

Correspondence to: Serdar Olt, MD, Adiyaman University Faculty of Medicine,

Department of Internal Medicine, Adiyaman, Turkey,

Phone: +905307774064

E-mail: serdarolt84@yahoo.com

\section{REFERENCES}

1. BAUMGARTNER RN, KOEHLER KM, GALLAGHER D, ROMERO L, HEYMSFIELD SB, ROSS RR, et al. Epidemiology of sarcopenia among the elderly in New Mexico. Am J Epidemiology. 1998; 147:755-63.

2. CESARI M, KRITCHEVSKY SB, NEWMAN AB, SIMONSICK EM, HARRIS TB, PENNINX BW, et al. Added value of physical performance measures in predicting adverse health-related events: results from the health, aging and body composition study. J Am Geriatr Soc 2009; 57: 251.

3. HEALTHY AGEING. Practical pointers on keeping well. WHO Western Pacific Regional Office 2005.

4. WHO, Global reports on diabetes. 2016: 25-26.

5. SHAW JE, SICREE RA, ZIMMET PZ. Global estimates of the prevalence of diabetes for 2010 and 2030. Diabetes Res Clin Pract 2010; 87: 4-14.

6. WANG H, HAI S, CAO L, ZHOU J, LIU P, DONG B-R. Estimation of prevalence of sarcopenia by using a new bioelectrical impedance analysis in Chinese community-dwelling elderly people. BMC Geriatrics. 2016; 16:216.

7. WANG T, FENG X, ZHOU J, GONG H, XİA S, WEİ Q, et al. Type 2 diabetes mellitus is associated with increased risks of sarcopenia and pre-sarcopenia in Chinese elderly. Sci Rep. 2016 Dec 13; 6:38937.

8. KIM TN, PARK MS, YANG SJ, YOO HJ, KANG HJ, SONG W, SEO JA, KIM SG, et al. Prevalence and determinant factors of sarcopenia in patients with type 2 diabetes: the Korean Sarcopenic Obesity Study (KSOS). Diabetes Care. $2010 \mathrm{Jul} ; 33$ (7):1497-9.

9. KALYANI RR, METTER EJ, EGAN J, GOLDEN SH, FERRUCCI L. Hyperglycemia predicts persistently lower muscle strength with aging. Diabetes Care. 2015;38:82-90.

10. PARK SW, GOODPASTER BH, STROTMEYER ES, KULLER LH, BROUDEAU R, KAMMERER C, et al. Health, aging, and body composition study. Accelerated loss of skeletal muscle strength in older adults with type 2 diabetes: the health, aging, and body composition study. Diabetes Care. 2007; 30:1507-1512.

11. PARK SW, GOODPASTER BH, LEE JS, KULLER LH, BOUDREAU R, DE REKENEIRE N, et al., Health, aging, and body composition study. Excessive loss of skeletal muscle mass in older adults with type 2 diabetes. Diabetes Care. 2009; 32:1993-1997.

12. SAYER AA, DENNISON EM, SYDDALL HE, GILBODY HJ, PHILLIPS DI, COOPER C. Type 2 diabetes, muscle strength, and impaired physical function: the tip of the iceberg? Diabetes Care. 2005; 28:2541-2542.

13. FUKUDA T, BOUCHI R, TAKEUCHI T, NAKANO Y, MURAKAMI M, MINAMI I, et al. Association of diabetic retinopathy with both sarcopenia and muscle quality in patients with type 2 diabetes: a cross-sectional study. BMJ Open Diabetes Research \& Care. 2017; 5 (1):e000404.

14. CHEN LK, LiU LK, WOO J ASSANTACHAI P, AUYEUNG TW, BAHYAH KS, et al. Sarcopenia in Asia: consensus report of the asian working group for sarcopenia. J AmMed Dir Assoc 2014; 15: 95-101.

15. BAHAT G, TUFAN A, TUFAN F, KILIC C, AKPINAR TS, KOSE M, et al. "Cut-off points to identify sarcopenia according to European Working Group on Sarcopenia in Older People [EWGSOP] definition.” Clin Nutr 2016; 35 (6): 1557-1563.

16. LANDI F, LIPEROTI R, FUSCO D MASTROPAOLO S, QUATTROCIOCCHI D, PROIA A, et al. Prevalence and risk factors of sarcopenia among nursing home older residents. J Gerontol A Biol Sci Med Sci 2012; 67: 48-55.

17. YU R, WONG M, LEUNG J, LEE J, AUYEUNG TW, WOO J. Prevalence, reversibility, risk factors and the protective effect of high body mass index against sarcopenia in community-dwelling older Chinese adults. Geriatr Gerontol Int 2014; 14 [Suppl 1]: 15-28.

18. WATERS DL, BAUMGARTNER RN. Sarcopenia and obesity. Clin Geriatr Med. 2011 Aug; 27 [3]:401-21.

19. BAUMGARTNER RN. Body composition in healthy aging. Ann N Y Acad Sci. 2000; 904:437-448.

20. KOHARA K. Sarcopenic obesity in aging population: current status and future directions for research. Endocrine. 2014; 45:15-25. 